\title{
JOGO PARA INCENTIVAR A SOCIALIZAÇÃO E APRENDIZAGEM DE CRIANÇAS AUTISTAS
}

\section{GAME TO ENCOURAGE THE SOCIALIZATION AND LEARNING OF AUTISTIC CHILDREN}

\author{
Letícia de Andrade Silva ${ }^{1}$ \\ Claudio Henrique da Silva² ${ }^{2}$ M.Sc. \\ (1) Universidade do Sul de Santa Catarina \\ e-mail: leticia.ands@gmail.com \\ (2) Universidade do Sul de Santa Catarina \\ e-mail: design@midiak.com.br
}

Palavras-chaves: Jogo, aprendizagem, autismo infantil.

\begin{abstract}
Na sociedade contemporânea, o convívio social e a comunicação são de vital importância para que consigamos exercer nosso papel como cidadão no mundo. Interagir com as pessoas e conseguir se comunicar com clareza são aspectos necessários na vida de todo ser humano, no entanto autistas podem apresentar reais dificuldades para realizar essas atividades. O autismo é uma alteração que afeta a capacidade de comunicação, socialização e comportamento da pessoa. O propósito do presente trabalho foi desenvolver um jogo que incentivasse a socialização e aprendizagem de crianças com Transtorno do Espectro Autista. O projeto foi realizado seguindo a metodologia de jogos desenvolvida pelo designer Ian Schreiber. O jogo foi testado em turmas com e sem crianças autistas. Os resultados preliminares foram promissores embora novas aplicações do jogo em um maior número de turmas mostrem-se necessárias para a pesquisa.
\end{abstract}

Keywords: Game, learning, infant autism.

In contemporary society, social interaction and communication are of vital importance, so we're able to exercise our role as a citizen in the world. Interacting with people and being able to communicate clearly are necessary aspects in every human being's life, however, autistic individuals may present real difficulties in carrying out these activities. Autism is a change that affects a person's ability to communicate, socialize, and behave. The purpose of the present work was to develop a game that encourages the socialization and learning of children with Autism Spectrum Disorder. The project was made following the games' methodology developed by the designer Ian Schreiber. The game was tested in classes with and without autistic children. The Preliminary results were promising, although new applications of the game in a larger number of classes prove necessary for the research. 
$16^{\circ}$ USIHC - Congresso Internacional de Ergonomia e Usabilidade de Interfaces Humano Computador

CINAHPA | 2017 - Congresso Internacional de Ambientes Hipermídia para Aprendizagem.

\section{Introdução}

Atualmente vivemos em um mundo social complexo, no qual o convívio com as pessoas e uma boa comunicação se fazem necessários. Segundo a ABRA, Associação Brasileira de Autismo (2016) "o autismo é uma alteração que afeta a capacidade de comunicação, socialização e comportamento da pessoa". Consequentemente, para os autistas há uma dificuldade em se encaixar na sociedade, em se comunicar e se expressar. No mundo, o Conselho Nacional de Saúde (2011) informa que a estimativa é de 70 milhões de pessoas com autismo, e na maioria dos casos, o autismo começa na infância.

De acordo com estudos do historiador e educador Piaget (1980), uma ferramenta facilitadora para interação social entre as crianças é o jogo. Neste artigo será apresentado o jogo que foi desenvolvido para incentivar a socialização e comunicação entre crianças autistas e crianças não-autistas no meio social.Desde que aLei $\mathrm{n}^{\circ} 12.764$, que institui a "Política Nacional de Proteção dos Direitos da Pessoa com Transtorno do Espectro Autista" foi aprovada, crianças autistas tem direito de frequentar escolas regulares. O principal ambiente social que as crianças frequentam e interagem com outras crianças é a escola, portanto trata-se de um jogo para ser usado em instituições de ensino, promovendo a socialização e a aprendizagem simultaneamente.

O Transtorno do Espectro Autista tornou-se parte da realidade de muitas famílias. Em termos de quantidade, o número oficial mais aceito no mundo é a estatística do $C D C$ (2014): uma criança com autismo para cada 68 crianças não- autistas, estima-se que esse número possa chegar a 2 milhões de crianças autistas no Brasil. Portanto, é possível observar que a síndrome afeta crianças em quantidade relativamente alta, revertendo-se em uma grande escala. A respeito de grandes escalas, o autor Victor Margolin escreveu sobre Design Social na sua obra "Politics of the Artificial" (2002), que "o designer tem a habilidade de projetar através da análise de problemas humanos em grande escala e contribuir para o bem-estar social". Esta é uma ideologia do Design Social, considerada no desenvolvimento deste projeto, juntamente com o Design Universal, que segundo Blücher (2005), trata-se de um design inclusivo, para todos. Ou seja, um jogo que todas as crianças possam jogar, sejam elas especiais ou não. Este projeto busca trazer acessibilidade, que, segundo Fernandes (2008), éo termo utilizado para garantir que todas as pessoas tenham acesso as áreas de seu convívio, como por exemplo espaços urbanos relacionados a educação, saúde e informação. $\mathrm{O}$ jogo abordado neste artigo busca tornar a escola um ambiente mais acessível para crianças autistas e não-autistas.

O jogo pode ser usado pelos professores para tornar as aulas mais inclusivas e servindo como ferramenta de fixação e validação do conteúdo estudado em sala, como também para incentivar a socialização e comunicação entre os aprendizes.

Dessa forma, pretende-se que o produto final deste projeto tragabenefício tanto para as instituições de ensino - as quais seria fornecido o material que facilitaria o exercício da Lei 12.764- quanto para os professores destas instituições, que receberiam apoio institucional e o modelo de uma atividade inclusiva, que consequentemente pode vir a melhorar a qualidade das aulas ministradas. Entretanto, o jogo é um material complementar, por isso não dispensa-se o material escolar normativo, como livros e apostilas. O domínio de conhecimento definido para o jogo refere-se à aprendizagem da Língua Inglesa. De acordo com o MEC (2015) "a Língua Inglesa é a mais disseminada e a mais ensinada no mundo inteiro", sendo de extrema importância para o mercado de trabalho e/ou desenvolvimento social.

$\mathrm{O}$ jogo apresentado neste artigo foi testado em rede regular de ensino, durante aulas de inglês. No entanto, com pequenas 
$16^{\circ}$ Ergodesign - Congresso Internacional de Ergonomia e Usabilidade de Interfaces Humano Tecnológica: Produto, Informações Ambientes Construídos e Transporte

$16^{\circ}$ USIHC - Congresso Internacional de Ergonomia e Usabilidade de Interfaces Humano Computador

CINAHPA | 2017 - Congresso Internacional de Ambientes Hipermídia para Aprendizagem

modificações, o jogo pode ser utilizado para outras disciplinastambém.

A faixa etária abordada neste projeto engloba crianças de 10 a12 anos, pois é a idade que tanto crianças de escolas públicas quanto de privadas tem aulas de inglês, os alunos de rede pública não tem aulas de inglês antes desta idade.

\section{Metodologia de Projeto}

A metodologia de projeto seguida foi a do game designer de jogos Ian Schreiber. De acordo com o Rochester Institute of Technology (2016), ele tornou-se uma referência para construção de jogos físicos e digitais. O diagrama da metodologia de jogo exposto a seguir (Figura1) foi montado de acordo o curso, ministrado por Ian Schreiber, chamado Game Design Concepts (2009), ensinando como criar jogos físicos.

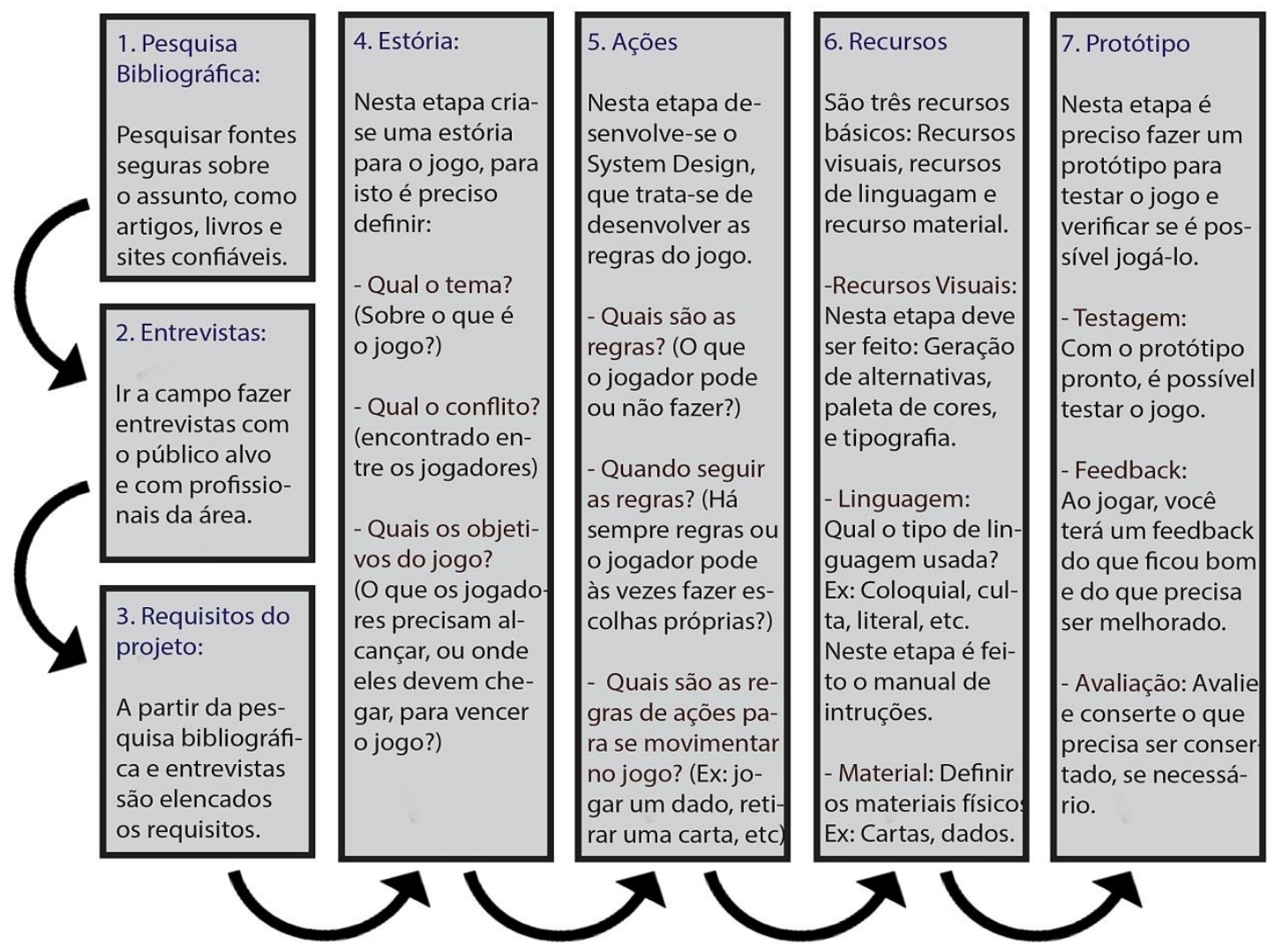

Figura 1: Metodologia de Projeto

\section{Bases teóricas}

O Design gráfico foi muito relevante neste projeto, pois engloba a organização de elementos visuais e textuais para alcançar boa comunicação entre o produto e o usuário. Nardi (2014) explica que "O designer gráfico é quem vai fazer a interface de acesso à informação. Seu papel está em fazer com que a população assimile essa informação da melhor forma". Então, procurou-se, através do design gráfico e do design de interação, criar uma interface entendível e atrativa para todas as crianças - autistas e não-autistas - que irão interagir com o jogo.

Jogos e materiais inclusivos são importantes na escola, e no caso de TEA (Transtorno do Espectro autista) é ideal que a inclusão comece desde cedo, pois de acordo com a ONG Autismo e Realizade (2013), o autismo não tem cura, mas pode ter os sintomas amenizados se for levado em consideração desde cedo. Uma pessoa autista jamais deve 
$16^{\circ}$ Ergodesign - Congresso Internacional de Ergonomia e Usabilidade de Interfaces Humano Tecnológica: Produto, Informações Ambientes Construídos e Transporte

$16^{\circ}$ USIHC - Congresso Internacional de Ergonomia e Usabilidade de Interfaces Humano Computador

CINAHPA | 2017 - Congresso Internacional de Ambientes Hipermídia para Aprendizagem.

ser vista como uma pessoa incapaz de vencer na vida, de ter uma carreira profissional e ser bem-sucedida, pois tem potencial de aprendizado, apenas necessita de devidos apoios.

O TEA é uma condição geral para um grupo de desordens complexas do desenvolvimento do cérebro. Esses distúrbios se caracterizam pela dificuldade nacomunicação social e comportamentos repetitivos. Embora todas as pessoas com TEA partilhem essas dificuldades, o seu estado irá afetá-las com intensidades diferentes, temos três tipos de intensidades dentro do espectro autista: $\mathrm{O}$ autista leve, moderado e severo, conforme descrito no Manual DSM-5(2016). Em concordância com Toledo (2008) o brincar foi, no passado, visto na educação infantil como um fator que atrapalhava o ensino, mas atualmente os pedagogos usam o brincar para ensinar o conteúdo, a intenção é que o aluno aprenda brincando.

\section{Pesquisa de campo}

Materiais, jogos e até mesmo brinquedos, voltados para crianças autistas são escassos. Isso dificulta a vida dos pais e professores que buscam uma educação inclusiva, pois se escolhessem optar pela compra desses produtos, praticamente não há opções no mercado. Em busca realizada nos dias 5 e 6 de Abril de 2016, em 8 lojas (Ri Happy, Havan, Lojas Americanas, Big, Toy Mania, Uni Duni Tê, Meninos \& Meninas e Lojas França) da região da Grande Florianópolis e lojas on-line, não foram encontrados brinquedos específicos para crianças autistas dessa idade.

De acordo com pesquisa de campo realizada em dez escolas regulares da grande Florianópolis, no mês de novembro de 2016, $90 \%$ dos professores afirmaram não se sentirem preparados para trabalhar com crianças autistas, e todos afirmaramnão ter material de apoio para usar com essas crianças, pois o material recebido é elaborado para crianças não autistas.

\section{Desenvolvimento do Jogo}

\section{Requisitos}

Ao desenvolver o processo de criação do jogo, foram elencados alguns requisitos. Os requisitos foram selecionados de acordo com pesquisas e estudos, e também de acordo com informações coletadas nas entrevistas em campo. Segue os requisitos:

- Linguagem literal: crianças autistas tem dificuldades em interpretar linguagem figurativa e expressões.

- Desenho gráfico predominantemente retilíneo: curvas aleatórias, movimentos irregulares, que não seguem um padrão organizado, podem vir a visualmente incomodar a criança autista.

- Mais recursos visuais do que textuais: tanto crianças autistas como não-autistas gostam de cores e imagens, textos muito longos devem ser evitados. A criação de uma linguagem gráfica através de símbolos éalgo facilitador para otimizar a compreensão por crianças autistas.

- Aplicável para alunos autistas e nãoautistas: O material deve servir para toda a classe, promovendo interação e inclusão.

- Abordagem de diversos conteúdos gramaticais: Os professores ressaltaram que gostariam de usar o jogo para aprendizagem de vários conteúdos do plano de ensino e não apenas para um único tema.

- Flexibilidade para o professor fazer alterações e adaptações: De acordo com o nível de conhecimento da turma e com o conteúdo abordado nas aulas, os professores podem alterar o nível de dificuldade do jogo e também acrescentar mais conteúdos/vocabulários/temas para serem aprendidos/praticados durante o jogo.

- Material reproduzível: materiais que sejam de fácil reprodução, para se caso o professor tiver uma turma maior, ele poder reproduzir várias cópias do jogo. Por isso, o jogo criado foi um jogo de tabuleiro com cartas, ambos podem ser impressos em papel, sendo reproduzidos quantos vezes forem necessárias.

Estória do Jogo 


\section{$16^{\circ}$ \\ ERGODESIGN USIHC CINAHPA}

Estória/contexto (o professor deve contar aos alunos): Imagine que você mora numa cidade distante, desconhecida pela maioria das pessoas, exceto pelas que nela habitam, e essa cidade precisa de um líder, que será o rei/rainha. São cinco candidatos para entrar na realeza, cada um vindo de uma parte diferente da cidade: $O$ soldado vindo do exército, o caçador vindo da floresta, o marinheiro vindo do alto mar, a dona de casa vindo do vilarejo e o empresário vindo do centro da cidade. $\mathrm{O}$ cargo de rei/rainha apenas poderá ser ocupado por alguém que souber responder algumas perguntas durante o jogo e simultaneamente acumular dinheiro suficiente para pagar a coroação no final do jogo.

Conflito: Há cinco candidatos à realeza. $\mathrm{O}$ conflito entre eles ocorre porque todos querem a coroa.

Objetivo: Se tornar o rei/rainha para vencer o jogo.

\section{Recursos Visuais}

\begin{abstract}
$16^{\circ}$ Ergodesign - Congresso Internacional de Ergonomia e Usabilidade de Interfaces Humano Tecnológica: Produto, Informações Ambientes Construídos e Transporte

$16^{\circ}$ USIHC - Congresso Internacional de Ergonomia e Usabilidade de Interfaces Humano Computador

CINAHPA | 2017 - Congresso Internacional de Ambientes Hipermídia para Aprendizagem.
\end{abstract}

Cores foram usadas como recurso para fazer os jogadores associarem informações. Como há cinco personagens, um de cada parte da cidade, foram definidas cinco cores: Verde, vermelho, azul, amarelo e marrom.As cores foram usadas com consistência para relacionar itens, relacionado o personagem com a parte da cidade que ele mora O jogo desenvolvido foi um jogo de tabuleiro, com cartas e com dinheiro fictício. $\mathrm{O}$ trajeto do tabuleiro foi desenhado em pentágono, pois é uma forma reta, geométrica e visualmente mais organizada do que desenhar um caminho curvo como a maioria dos jogos de tabuleiro. Assim foi feito, pois este é um requisito do projeto.

O desenvolvimento do projeto gráfico foi realizado com auxílio de dois programas da Adobe: Illustrator e Photoshop. A seguir (Figura 2) expõe-se o resultado final do projeto. 


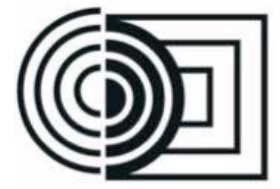

$16^{\circ}$

ERGODESIGN

USIHC CINAHPA $16^{\circ}$ Ergodesign - Congresso Internacional de Ergonomia e Usabilidade de Interfaces Humano Tecnológica: Produto, Informações Ambientes Construídos e Transporte

$16^{\circ}$ USIHC - Congresso Internacional de Ergonomia e Usabilidade de Interfaces Humano Computador

CINAHPA | 2017 - Congresso Internacional de Ambientes Hipermídia para Aprendizagem.

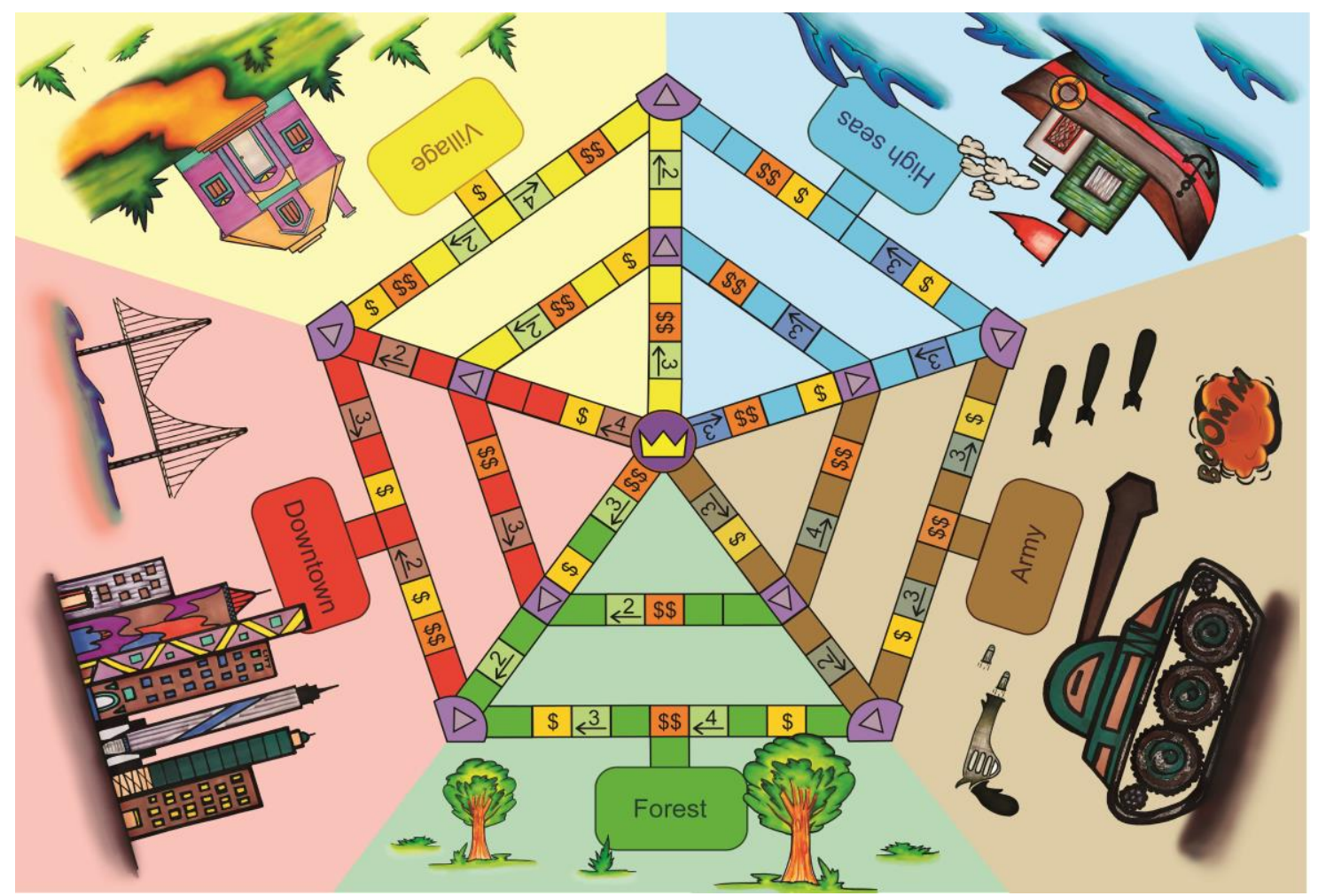

Figura 2 - Tabuleiro Final

Elementos e materiais do jogo:

1. Uma pilha de cartas com questões/perguntas/desafios (de acordo com conteúdo estudado em sala)

Exemplo: Verbos Modais (Figura 3).

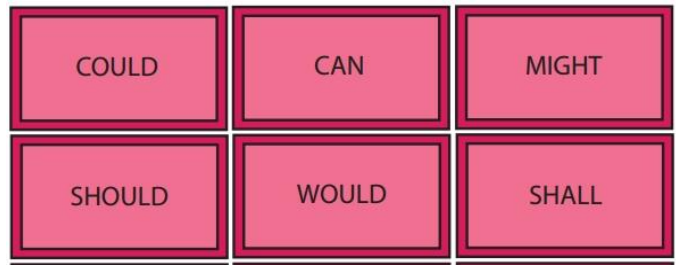

(Figura 3 - Cartas Questões)

2. Uma pilha de dólares: dinheiro fictício impresso em papel, como na figura 4.
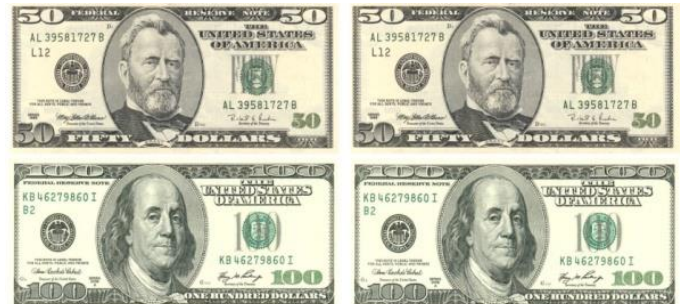

Figura 4 - Dólar fictício

3. Uma pilha de cartas que determinam a quantidade de dólares que o jogador ganha/perde durante o jogo (Figura 5).

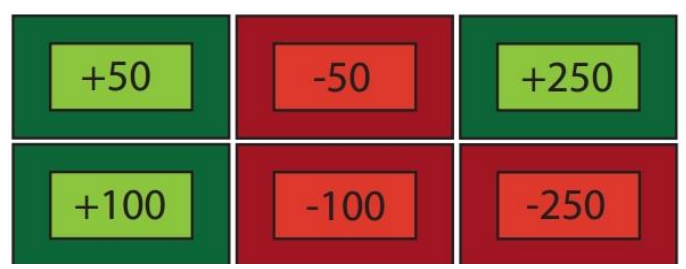

Figura 5 - Cartas Determinantes 


\section{$16^{\circ}$ \\ ERGODESIGN USIHC CINAHPA}

4. O tabuleiro impresso (Em folha tamanho A1, ou oito folhas A4). Imprimir de acordo com o número de alunos, 1 tabuleiro a cada 5 alunos. Exemplo: Para uma classe com 20 alunos, imprimir 4 tabuleiros.

5. Dois dados em cubo e um dado triangular. Estes dados são confeccionados com aimpressão em papel, dobragem manual e cola. Todos são feitos com os moldes mostrados a seguir na figura 6 .

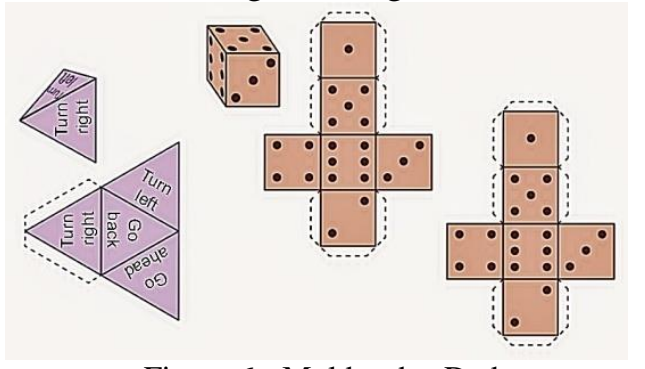

Figura 6 - Moldes dos Dados

6. Cinco cartas com o nome de cada personagem do jogo (Marinheiro, soldado, caçador, dona de casa e empresário) como ilustra figura 7. Estas cartas serão distribuidas entre os cinco jogadores, cada um será um personagem.

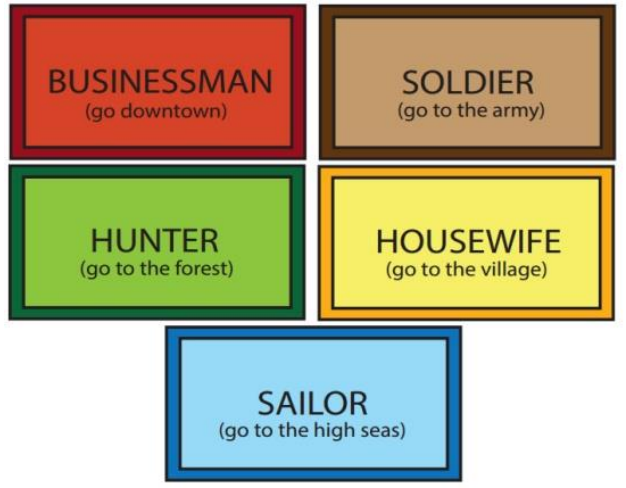

Figura 7 - Cartas Personagens

7. Cinco peões, para fazer a movimentação no tabuleiro. Material escolhido pelo professor.Sugestão: tampinhas de garrafa ou rolhas coloridas (o professor pode incentivar o aluno a personalizar seu peão, pintar com guache, colar adesivos, etc).

No jogo, há uma linguagem gráfica, para que o jogador associe que determinado $16^{\circ}$ Ergodesign - Congresso Internacional de Ergonomia e Usabilidade de Interfaces Humano Tecnológica: Produto, Informações Ambientes Construídos e Transporte

$16^{\circ}$ USIHC - Congresso Internacional de Ergonomia e Usabilidade de Interfaces Humano Computador

CINAHPA | 2017 - Congresso Internacional de Ambientes Hipermídia para Aprendizagem.

símbolo significa determinada ação. Em resumo, para poder jogar o dado, o jogador precisa retirar uma carta da pilha de cartas com perguntas (Figura 3), e responder a questão. Se ele responder correto, ele pode jogar os dois dados cúbicos ao mesmo tempo (chance de andar mais casas) e ganha 100 dólares. Se o jogador responder parcialmente correto, ele pode jogar apenas um dado cúbico e ganha 50 dólares. As cartas não precisam ser sempre perguntas, por exemplo: podem ser palavras em inglês (como os verbos modais) e $o$ aluno tem que falar uma frase com aquela palavra, ou dizer o significado da palavra. Depois de responder a pergunta, joga-se o dado e o peão do jogador pode cair em casas marcadas pela seguinte linguagem gráfica: \$ (um cifrão): o jogador pega uma carta do tipo mostrado no item 3 da lista ao lado. Se a carta for verde, ele ganha o valor mostrado na carta em dolar. Se for carta vermelha, ele perde o dinheiro.

\$ (dois cifrões): O mesmo esquema do \$, porém ele pega a carta do item 3 e entrega para um colega, portanto, o colega escolhido que perde/ganha dinheiro.

Um triângulo: Joga o dado triangular lilás, que mostra a direção que deve andar no tabuleiro. (ex: para frente ou para trás)

Número com uma fecha.: A quantidade de casas e a direção que seu peão deve se mover. Exemplo: 3 casas para frente ou duas casas para trás. Segue-se o número e a direção da flecha indicada na casa.

Vence o jogo quem chegar na casa com a Coroa e tiver 1000 dólares para pagar pela sua coroação. Se chegar na coroa sem o dinheiro, o jogador continua jogando até conseguir o valor que falta.

\section{Aplicação do Jogo}

O jogo foi aplicado como estratégia de aula com quatro turmas de alunos na Escola Yázigi (Figura 8). Uma destas turmas tem uma criança autista. Em relação ao feedback, todos os alunos, inclusive o aluno autista, conseguiram jogar com facilidade e sem ter dúvidas em relação a jogabilidade do jogo. Os alunos respondiam as questões das cartas, 


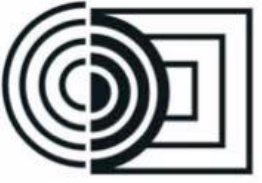

praticando o conteúdo sem perceber, aprendendo brincando.

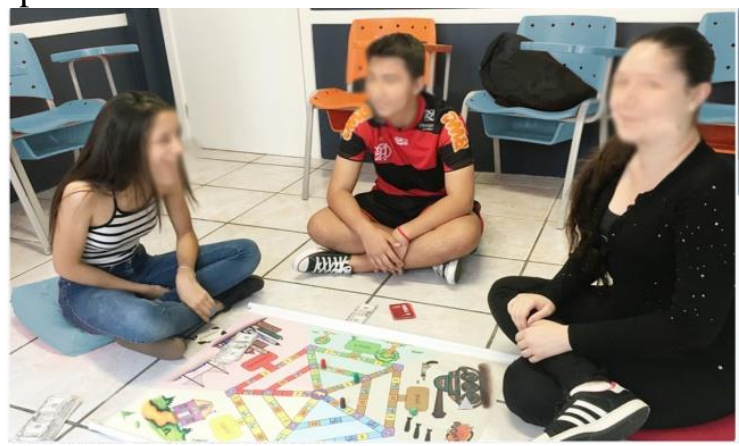

Figura 8: Alunos jogando no Yázigi.

\section{Conclusão}

$\mathrm{O}$ projeto funcionou como previsto e os objetivos do jogo foram alcançados. $\mathrm{O}$ aluno autista brincou e participou com os colegas, o idioma foi praticado e aprendido.

Normalmente, esse aluno autista tem problemas de foco, concentração e fala pouco, mas durante o jogo ele reagiu diferente, prestando atenção e observando cada movimento que alguém fazia no tabuleiro. Durante o jogo, usou as cartas corretamente para falar frases com clareza em inglês. Os alunos ficaram empolgados e pediram para jogar novamente na próxima aula. Foi gratificante ver que o projeto funcionou bem ao ser colocado em prática.

Apesar de o jogo funcionar bem para um aluno autista, isso não significa que funcionará bem para qualquer aluno autista. Há limitações, pois o autismo é um espectro: TEA - Transtorno do Espectro Autista. O termo "espectro" nos mostra que há várias intensidades, ou seja, cada criança autista é diferente da outra. A capacidade da criança de interação e aprendizagem geralmente varia de acordo com a intensidade de autismo que a criança apresenta ao ser diagnosticada, autistas leves e moderados normalmente se desenvolvem com mais facilidade do que autistas severos. Foi possível observar que o jogo funcionou com um autista moderado. Embora os resultados preliminares tenham se mostrado promissores, novas aplicações em outras turmas envolvendo crianças autistas, inclusive de outros espectros, devem ser

\footnotetext{
$16^{\circ}$ Ergodesign - Congresso Internacional de Ergonomia e Usabilidade de Interfaces Humano Tecnológica: Produto, Informações Ambientes Construídos e Transporte

$16^{\circ}$ USIHC - Congresso Internacional de Ergonomia e Usabilidade de Interfaces Humano Computador

CINAHPA | 2017 - Congresso Internacional de Ambientes Hipermídia para Aprendizagem.
}

realizadas. Como cada espectro não apresenta as mesmas características, não há certezas, nem comprovações de que o jogo funcionaria bem com o espectro inteiro.

\section{BIBLIOGRAFIA}

ABRA, A definição do que é o autismo,

Disponível em:

$<$ http://www.salvemascriancas.org/wp/?p=1014 6> Acesso em: 05 de abril. 2016.

BLUCHER, Edgar. Ergonomia: Projeto e produção. São Paulo, 2005.

CDC, Fatos sobre o autismo. Disponível em:http://www.cdc.gov/ncbddd/autism/facts.ht ml> Acesso em: 12 de abril. 2016.

CONSELHO NACIONAL DE SAÚDE, Conscientização do autismo. Disponível em: $<$ http://conselho.saude.gov.br/ultimas notici as/2011/01 abr autismo.html> Acesso em: 01 de abril. 2016.

FERNANDES, Edicléa. Acessibilidade e inclusão social. Rio de Janeiro, 2008.

GAME DESIGN CONCEPTS. Como fazer jogos. Disponível em:

<https://gamedesignconcepts.wordpress.com>

Acesso em: 20 de setembro.

ONG AUTISMO E REALIDADE, O que é o autismo. Disponível em:

$<$ http://autismoerealidade.org/informe-se/sobreo-autismo/o-que-e-autismo/> Acesso em: $01 \mathrm{de}$ Março. 2016.

PIAGET, J.; INHELDER, B. A psicologia da criança. 6. ed. São Paulo, Rio deJaneiro: Difel, 1980.

MARGOLIN,V. Politics of the

Artificial.University Of Chicago Press, $3^{\mathrm{a}}$

Edição. Chicago, 2002. p.61.

\section{MANUAL DSM-5, Definição de Autismo e} suas intensidades. Disponível em: $<$ http://www.psychiatry.org/psychiatrists/practic e/dsm> Acesso em: 02 de fev. 2017.

MEC, Informações sobre a Língua Inglesa. Disponível em: 


\section{$16^{\circ}$ \\ ERGODESIGN USIHC CINAHPA}

$<$ http://portal.mec.gov.br/component/content/art icle?id=40361\#nem_pergunta11 > Acesso em: 07 de nov. 2017.

NARDI, Henrique. UNESP em entrevista para graduando da USP. Disponível em: $<$ http://www.fau.usp.br/fauforma/2015/assets/ric ardo yamamoto.pdf $>$ Acesso em: 14 de Jun. 2016

ROCHESTER INSTITUTE OF

TECHNOLOGY, Sobre Ian Schrieber.

Disponível em:

<https://www.rit.edu/gccis/igm/ian-schrieber>

Acesso em: 22 de nov. 2016 $16^{\circ}$ Ergodesign - Congresso Internacional de Ergonomia e Usabilidade de Interfaces Humano Tecnológica: Produto, Informações Ambientes Construídos e Transporte

$16^{\circ}$ USIHC - Congresso Internacional de Ergonomia e Usabilidade de Interfaces Humano Computador

CINAHPA | 2017 - Congresso Internacional de Ambientes Hipermídia para Aprendizagem.

TOLEDO, Cristina. O brincar e a constituição de identidades. Rio de Janeiro, Niterói, 2008.

\section{Agradecimentos}

Este projeto tornou-se possível com o apoio de professores entrevistados, alunos jogando o jogo, amigos emprestando livros, etc. Sou grata à todos, mas o meu agradecimeto final vai para o Prof. Claudio H. Silva da UNISUL e para meus pais, por me apoiarem durante toda essa aventura. 